\title{
Understanding suicidality among teenagers and adults suffering epilepsy using a big data, machine learning analysis of digital conversations.
}

\section{T. Faicone', E Pestana-Knight 'A. Dagar', R. Castilia-Puentes ${ }^{3}$, A. Anand1, C. Brethenoux², L. Valieta², P.}

Furey ${ }^{2}, \mathrm{~J}$

TimmonsMitchell ${ }^{41}$ Cleveland Clinic Foundation ${ }^{2}$ Cultureinte/ ${ }^{3}$ Johnson and Johnson ${ }^{4}$ Case Western Reserve University

\section{Introduction}

- Epilepsy is the fourth most common neurologic disorder and depression is noted in $30-50 \%$ of people with epilepsy (PWE).

- In a review of several meta-analysis, suicide accounted for $32 \%$ of the deaths of patients with epilepsy.

- Prior research has reported estimated annual rate for suicide among adults with epilepsy $22 \%$ higher than in the general population.

- One of the major drivers for suicidal thoughts in people with epilepsy is the high incidence of depression in this population.

- Social media has become one of the most common medium of interpersonal communication.

- Digital conversations among PWE may provide a window to understand the fears and concerns about the disease and their mental state.

\section{Objectives}

- To mine spontaneous conversations about suicide from the voice of teens and adults with epilepsy in the USA, in order to understand key topics, mindsets, sentiments and the main drivers for the suicidal thoughts.

- To identify how teens mindset differ from adult mindset when talking about suicide and epilepsy.

- To get insight about the implications of having epilepsy in teens.

\section{Methods}

- The population of interest were self-identified teenager and adult users online who endorsed suffering from epilepsy.

- CulturIntel used their advanced software platform to mine and structure qualitative digital conversations on epilepsy and suicide.

- The search was limited to a 12-month period (September 26, 2017 through September 25, 2018).

- The search was limited to US based IP addresses.

- The data mining and collection occurred across various relevant sites (topical sites, blogs, social network \& message boards).

- To avoid duplicity, a single user with multiple posts/comments within a conversation was counted once.

\section{Results}

- A total of 222,000 digital conversations about epilepsy were posted online during the study period.

- Of all the discussions, a total of 41,000 were posted online by teenagers and 181,000 by adults.

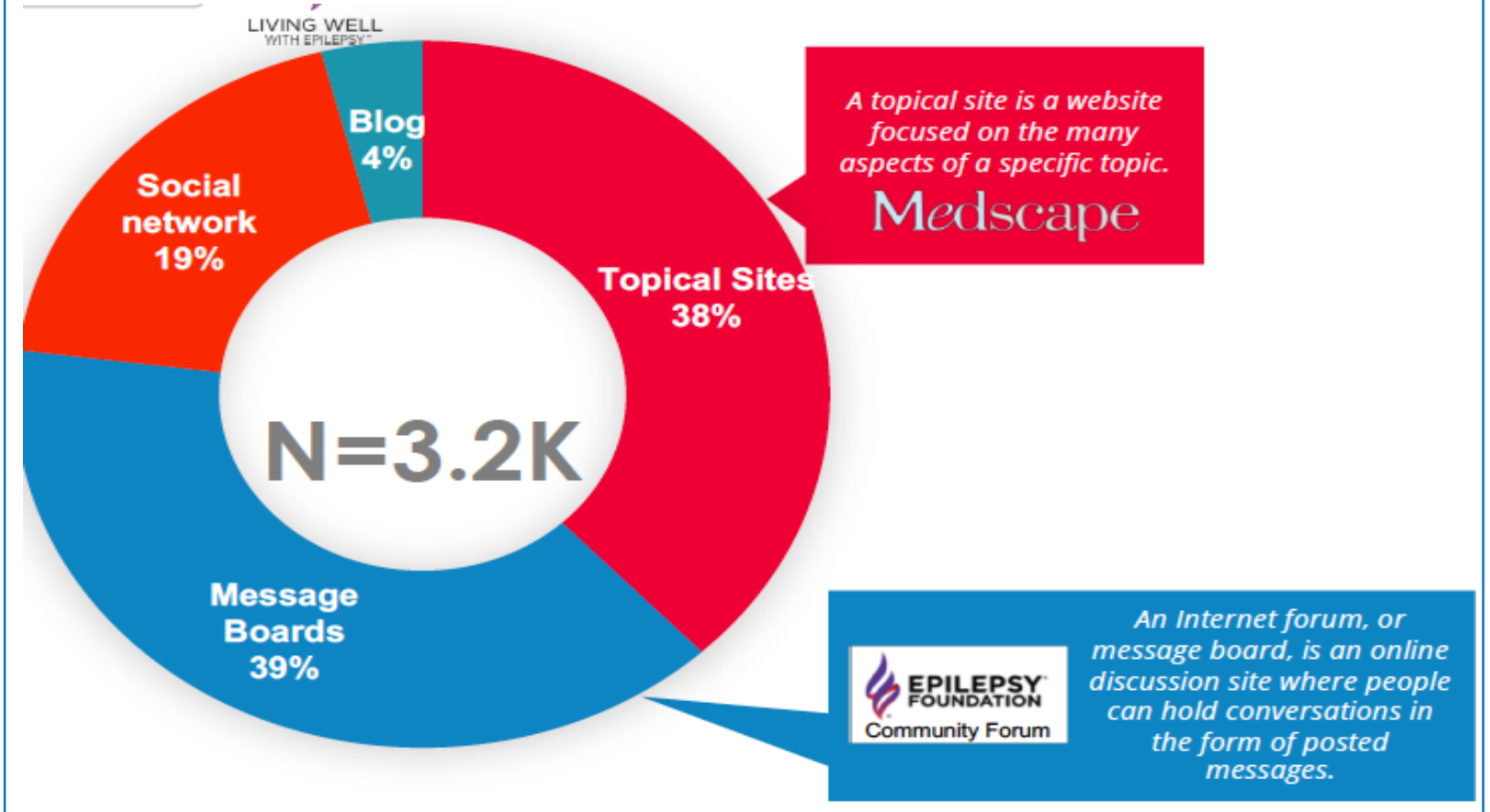

Figure 1: Origins of posts on suicide and epilepsy among teenagers.
- Further analysis showed that, 3200 (8\%) of posts among teens were related to suicide compared to 5800 (3\%) among adults

- Content analysis showed that $30 \%$ of posts by teenagers discussed social consequences of seizures compared to $21 \%$ posts by adults.

- Another $29 \%$ of posts by teenagers were looking for emotional support to deal with the impact of the illness compared to $19 \%$ adults.

- In contrast to above findings, concerns about physical impairments from seizure were expressed in $29 \%$ posts by adults compared to $21 \%$ teenagers.
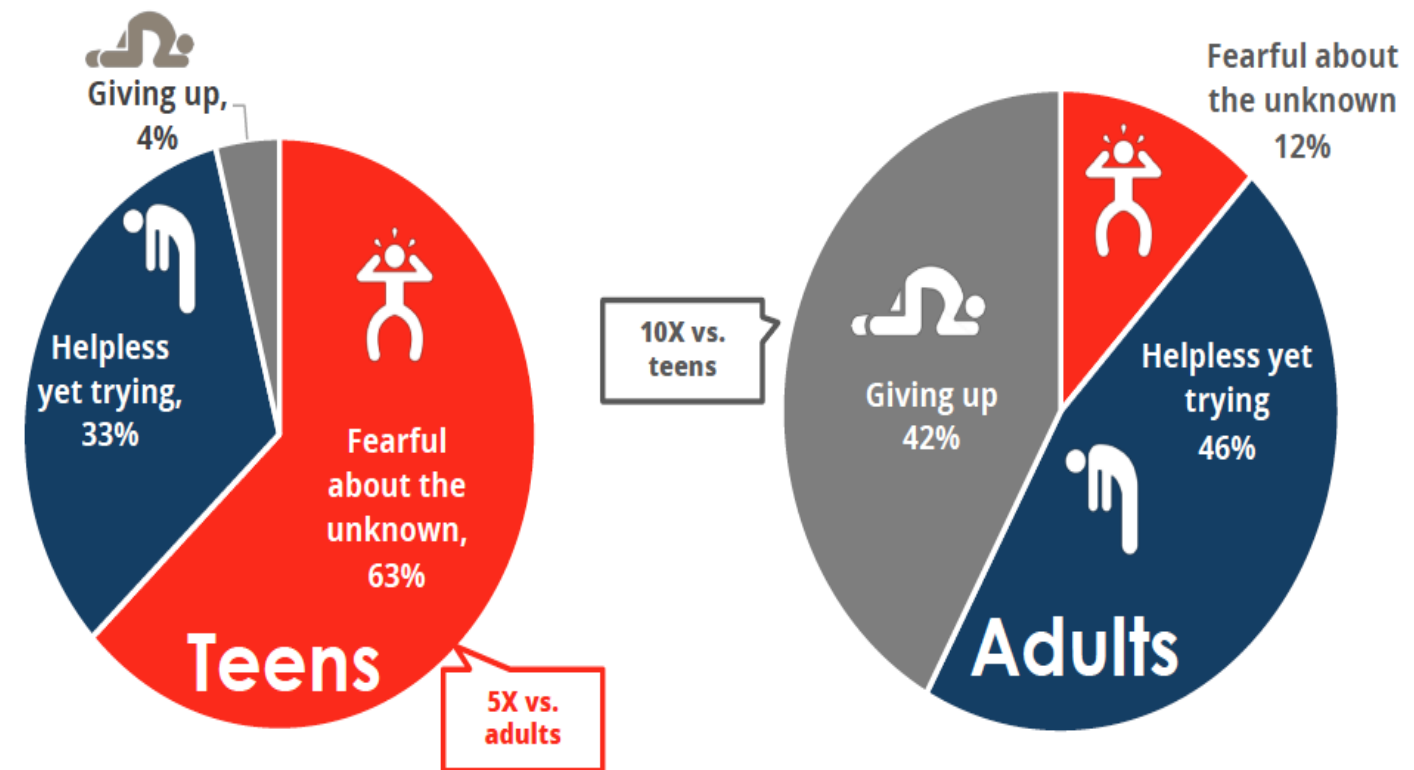

Figure 2. Mindset analysis: teenagers and

\begin{tabular}{|c|c|c|c|c|}
\hline \multirow[t]{4}{*}{$\begin{array}{l}\text { Drivers }(\mathrm{n}) \\
\text { Negative drivers } \\
\text { (barriers) } \\
\mathrm{N}=\mathbf{2 1 0 0}\end{array}$} & Feeling alone & $\begin{array}{l}\text { Teens } \\
(\%) \\
32\end{array}$ & $\begin{array}{l}\text { Adults } \\
\text { (\%) } \\
23\end{array}$ & $\begin{array}{l}\text { Quotes from Teenagers } \\
\text { "I'm } 16 \text { and...I was wondering if anyone else feels kinda } \\
\text { alone with epilepsy and like when you tell someone } \\
\text { they'll just freak out...." }\end{array}$ \\
\hline & Low spirit & 28 & 17 & $\begin{array}{l}\text { "My math teacher called me up in front of the class and } \\
\text { said, "If you feel like 'something' is going to happen, } \\
\text { just leave the room." there was a huge amount of } \\
\text { twittering and giggling!" }\end{array}$ \\
\hline & $\begin{array}{l}\text { Social } \\
\text { embarassme } \\
\text { nt }\end{array}$ & 25 & 31 & $\begin{array}{l}\text { "I am having a really hard time lately... I'm very } \\
\text { depressed (suicidal even), and not finding much joy in } \\
\text { life." }\end{array}$ \\
\hline & Sense of loss & 15 & 29 & $\begin{array}{l}\text { “I'm just super annoyed with my epilepsy. It's been } \\
\text { limiting what I can do...I can't do anything. Not only } \\
\text { have I been having more seizures, but I also have panic } \\
\text { and anxiety attacks.” }\end{array}$ \\
\hline \multirow[t]{3}{*}{$\begin{array}{l}\text { Positive drivers } \\
\mathrm{N}=96\end{array}$} & $\begin{array}{l}\text { Encouragem } \\
\text { ent via } \\
\text { connection }\end{array}$ & 50 & 38 & $\begin{array}{l}\text { "I haven't been treated any differently around my } \\
\text { friends because of my epilepsy but I have GREAT } \\
\text { friends." }\end{array}$ \\
\hline & $\begin{array}{l}\text { Empowerme } \\
\text { nt over the } \\
\text { epilepsy }\end{array}$ & 41 & 23 & $\begin{array}{l}\text { "Forget the shame u may feel figure out what it is u } \\
\text { wanna do in life make it happen it's all still possible." }\end{array}$ \\
\hline & $\begin{array}{l}\text { Adaptation } \\
\text { to epilepsy }\end{array}$ & 9 & 39 & $\begin{array}{l}\text { "Asking myself "Why me" I'm on my 3rd year of gran } \\
\text { mal epilepsy disorder doing much better... " }\end{array}$ \\
\hline \multirow[t]{3}{*}{$\begin{array}{l}\text { Neutral drivers } \\
\mathrm{N}=960\end{array}$} & $\begin{array}{l}\text { Emotional } \\
\text { connection }\end{array}$ & 45 & 29 & $\begin{array}{l}\text { "I was diagnosed with epilepsy about } 6 \text { months ago and } \\
\text { I have been having some trouble processing everything. }\end{array}$ \\
\hline & Support & 37 & 22 & $\begin{array}{l}\text { "Hey everyone!...I was wondering if anyone would like } \\
\text { me to start a snapchat so we could chat on there?" }\end{array}$ \\
\hline & $\begin{array}{l}\text { Information } \\
\text { and } \\
\text { resources }\end{array}$ & 18 & 49 & $\begin{array}{l}\text { "Hey everyone... I got epilepsy when I was two } 1 / 2 . . . \text { I } \\
\text { am trying to look for a support group and meet new } \\
\text { people in my area with epilepsy... Does anyone know } \\
\text { any places? I am going to try this one too." }\end{array}$ \\
\hline
\end{tabular}

Table 1: Sentiment analysis of conversation 'drivers

\section{Conclusions}

- We present one of the first big data analysis of online conversations among epilepsy patients expressing suicidality.

- The internet seems to provide a much-needed outlet for PWE whose disease can cause isolation and insecurity regarding connecting with others in direct social situations.

- We found important differences in the concerns and the shared sentiments among teenagers and adults regarding coping with the disease.

- This knowledge could be used during the counselling of PWE regarding depression and suicide prevention. 